\title{
Form and function in juvenile ascidians. II. Ontogenetic scaling of volumetric flow rates
}

\author{
Kristin M. Sherrard ${ }^{1,3, *}$, Michael LaBarbera ${ }^{1,2}$ \\ ${ }^{1}$ Committee on Evolutionary Biology and ${ }^{2}$ Department of Organismal Biology and Anatomy, University of Chicago, Chicago, \\ Illinois 60637, USA \\ ${ }^{3}$ Present address: Friday Harbor Laboratories, 620 University Road, Friday Harbor, Washington 98250, USA
}

\begin{abstract}
Very little is known of the challenges to suspension feeding performance facing early juvenile marine invertebrates, although scaling considerations suggest juveniles are often at a disadvantage. For example, early juvenile ascidians have relatively, as well as absolutely, narrower siphons than later stages, generating high resistance to flow (Sherrard \& LaBarbera 2005: Mar Ecol Prog Ser 287:127-138, this issue). To test whether feeding flow rates are correspondingly decremented in early juveniles, we measured volumetric flow rates during the ontogeny of 4 species of ascidians, 2 solitary and 2 colonial. Early juveniles of all species had relatively lower flow rates than adults. They exhibited rapid, positively allometric increases in volumetric flow rates with respect to body size, followed in the solitary species by slightly positively allometric increases thereafter. Positively allometric scaling occurred within different size ranges depending on species and appears to be driven by reduced resistance as siphons expand rather than a shift in hydrodynamic regime. By 2 to $3 \mathrm{wk}$ after settlement, juveniles of solitary species generated size-specific volumetric flow rates nearly as high as those found in adults. Juveniles of the colonial species Distaplia occidentalis had superior feeding performance at small size compared with solitary juveniles, but juveniles of another colonial species Botrylloides violaceus did not. Because ascidian larvae are non-feeding, early juveniles probably benefit from feeding as soon as possible, even at lower efficiency.
\end{abstract}

KEY WORDS: Ascidian · Early juvenile $\cdot$ Ontogenetic scaling $\cdot$ Suspension feeding

\section{INTRODUCTION}

Early juvenile marine invertebrates as small as 200 microns in length live independently (FialaMedioni 1978a, 1978b), often with the same lifestyles and in the same habitats as conspecific adults. Scaling considerations strongly suggest that small size challenges many functions and indeed early juveniles have disproportionately high mortality rates (Gosselin \& Qian 1997, Hunt \& Scheibling 1997). However, very little is known about any aspect of performance in early juvenile marine invertebrates (Moran \& Emlet 2001). Feeding performance is particularly important in early juveniles, strongly affecting individual survival, growth rate and fecundity, as well as competitive interactions and species ranges (Stoner 1990, Osman \&
Whitlatch 1996). However, is it not clear to what extent natural selection would optimize feeding performance in juveniles that are morphologically and functionally similar to adults.

A wide variety of marine invertebrates suspension feed, including ascidians, bivalves, polychaetes, barnacles, cnidarians, brachiopods and many larval forms, and their growth rates have been strongly tied to food intake (Paulay et al. 1985, Lesser et al. 1994, Armsworthy et al. 2001), and hence to feeding proficiency. Suspension feeding performance is readily assessed by measurements such as volumetric flow rates, resistance, pressure drop, pump power requirements and particle retention efficiency.

Early juveniles may face size-related disadvantages to efficient suspension feeding. For example, Declerk 
(1995) found that many species of suspension feeding gastropods graze when small and only switch to suspension feeding at a larger size. She suggested that juveniles were less efficient suspension feeders than adults because of the cost of pumping fluid through a small mantle cavity. Beninger et al. (1994) found that Pecten maximus juveniles have gills that are less efficient at capturing food than adult gills until 42 to $58 \mathrm{~d}$ after settlement, and Chaparro et al. (2001) found that Ostrea chilensis under 1 mo old do not yet have a gill morphology compatible with adult function. Finally, theoretical modeling of ciliary suspension feeders suggests that small suspension feeders pumping fluid through enclosed areas face strong biomechanical challenges (Grunbaum et al. 1998).

In a previous study (Sherrard \& LaBarbera 2005, this issue), we found that early juvenile ascidians have relatively narrower siphons than adults as they complete development after beginning to feed. A narrower siphon generates a higher resistance to flow and juveniles have no compensatory elevation in the length of stigmatal perimeter (proportional to number of cilia) that drives flow. Hence, we would expect early juvenile ascidians to have lower size-specific volumetric flow rates than adults. Even if the siphons were not relatively narrower in juveniles, their absolutely small size would generate greater resistance. Fluid flow through the miniscule siphons of an early juvenile is highly viscous, similar to sucking honey through a straw. Thus, it is probably disproportionately costly for juveniles to actively suspension feed compared with adults.

We compare solitary and colonial ascidians to disentangle the effects of size and development on feeding performance. Juveniles of colonial species begin feeding at several hundred times the volume of the solitary species' juveniles. Size per se turns out to be less important than developmental stage in determining relative feeding performance.

\section{MATERIALS AND METHODS}

We collected adults and settled and maintained juveniles, as described in Sherrard \& LaBarbera (2005). Our size metric for the scaling relationships is 'linear size', the square root of lateral body area. Based on correlations with dry mass and ash-free dry mass, linear size provides a biologically sound metric for scaling comparisons among different sizes and species (Sherrard \& LaBarbera 2005).

Flow velocity measurements. Particle image velocimetry allows non-invasive observation of natural feeding using food particles at low concentrations as flow markers. Although the animals were observed in a $1 \times 3 \times 5 \mathrm{~cm}$ chamber, wall effects are not an issue because ascidians live close to a substrate in nature.

We videotaped juveniles and adults feeding through either an Olympus BH2 trinocular compound microscope or a Wild Leica MZ6 trinocular dissecting microscope. Images were captured using a Sony $3 \mathrm{CCD}$ video camera (SSC-S20) and recorded to a Sony TRV900 digital video recorder. We videotaped movement of Rhodamonas and Isochrysis cells into the incurrent siphon in side view (focus set to the mid-siphon region) for 3 to $5 \mathrm{~min}$ of steady, relaxed feeding in still water (Fig. 1). We maintained ambient summer seawater temperatures of 11.0 to $12.5^{\circ} \mathrm{C}$ using a cooling stage. We recorded individual oozooids (the initial zooid derived from the larva) of colonial species from 0 to $12 \mathrm{~d}$ after settlement. Individuals of solitary species, which grow more slowly and do not begin feeding until at least $5 \mathrm{~d}$ after settlement, were recorded 5 to $75 \mathrm{~d}$ after settlement.

We measured incurrent velocities of 35 to 45 individuals covering the entire ontogeny in each species, from newly feeding juveniles to large adults for solitary species and to the addition of multiple zooids for colonial species. Where possible, we measured individuals repeatedly through their ontogenies. To obtain velocity and volumetric flow estimates, we used NIH Image 1.62 to digitize a minimum of 15 in-focus particle entry paths per individual at each size. We only used particles whose paths were in focus for at least 5 consecutive frames $(t=0.17 \mathrm{~s})$, that approached to within $1 / 10$ of a siphon diameter and whose correlation coefficient for 2nd order polynomial curve fits was above 0.95. Measurements of a single instance of particle entry were repeatable within $\pm 2 \%$ for entry velocity; individual volumetric flow estimates were repeatable within $\pm 4 \%$.

Velocity estimates using the particle tracking method depend on the assumption that particles move only in the plane of view and that the viewing plane lies along a siphon diameter. Thus, any vertical component to the movement (constrained by focal depth on the compound microscope to a maximum of 60 microns) was undetectable; measured velocities may be lower than their true values. Additionally, particles may have entered the siphon up to $30 \mu \mathrm{m}$ above or below the diameter line, in a region where flow velocities were lower, causing axial velocity to be underestimated.

We estimated average entry velocity as the average, weighted 3-dimensionally, of maximal local velocities across the siphon from edge to center. Volumetric flow rate is defined by average velocity $\times$ the siphon crosssectional area. Because measurement error was low, and other uncertainties of measurement result solely in 
underestimates of velocity, this is a conservative method of estimating average inflow velocity.

Short-term measurements of incurrent flow velocity are representative of overall flow velocities, because a steadily feeding ascidian at constant temperature does not vary its pumping rate (Fiala-Medioni 1978b, 1978c). Furthermore, though interspecific or withinontogeny differences in retention or digestion efficiency may exist, they would have to be substantial to reverse the effects of observed large ontogenetic changes in volumetric flow rate.

Pump properties. The relative importance of inertial and viscous forces is specified by the Reynolds number (Re), a dimensionless ratio (Vogel 1994):

$$
\operatorname{Re}=\frac{U L}{v}
$$

where $U=$ fluid velocity, $v=$ kinematic viscosity and $L$ $=$ characteristic length. Early juvenile ascidians have a Re of about 0.1 in their incurrent siphons, while adults have siphonal Re's of hundreds. At lower siphonal Re, resistance is higher, generally reducing the volumetric flow rate.

Pressure drop, the product of resistance and volumetric flow rate, describes how much potential energy is required to drive flow through a system. Riisgård (1988) divided the total pressure drop associated with pumping fluid through ascidians into 3 separate components, termed frictional, mucous net and kinetic energy pressure drops. Although he found them to have approximately equal magnitudes in adult ascidians, scaling considerations suggest that their magnitudes are unequal in small juveniles. In early juveniles, kinetic energy pressure drop, which is proportional to the square of excurrent velocity, must be a trivial portion of total pressure drop since current velocities are slow. Similarly, mucous net pressure drop, proportional to basket area, contributes a small fraction of total pressure drop in small animals. On the other hand, frictional pressure drop scales as the inverse of internal radius, and thus constitutes by far the largest proportion of systemic pressure drop for early juveniles. Frictional pressure drop is caused by compression of flow lines into the siphon and by the slowing of flow along the siphon and filter surfaces.

We estimated total pressure drop in juveniles from incurrent siphonal pressure drop, the product of siphonal resistance (resistance to flow through a circular aperture, Vogel 1994) and volumetric flow rate $\left(\pi r^{2} V\right)$ :

$$
\Delta P_{\text {siph }}=\frac{3 \pi \mu V}{r}
$$

where $\mu=$ dynamic viscosity of seawater $\left(1.072 \times 10^{-3}\right.$ $\mathrm{Pa} \cdot \mathrm{s}$ at $\left.20^{\circ} \mathrm{C}\right), V=$ average incurrent velocity and $r=$

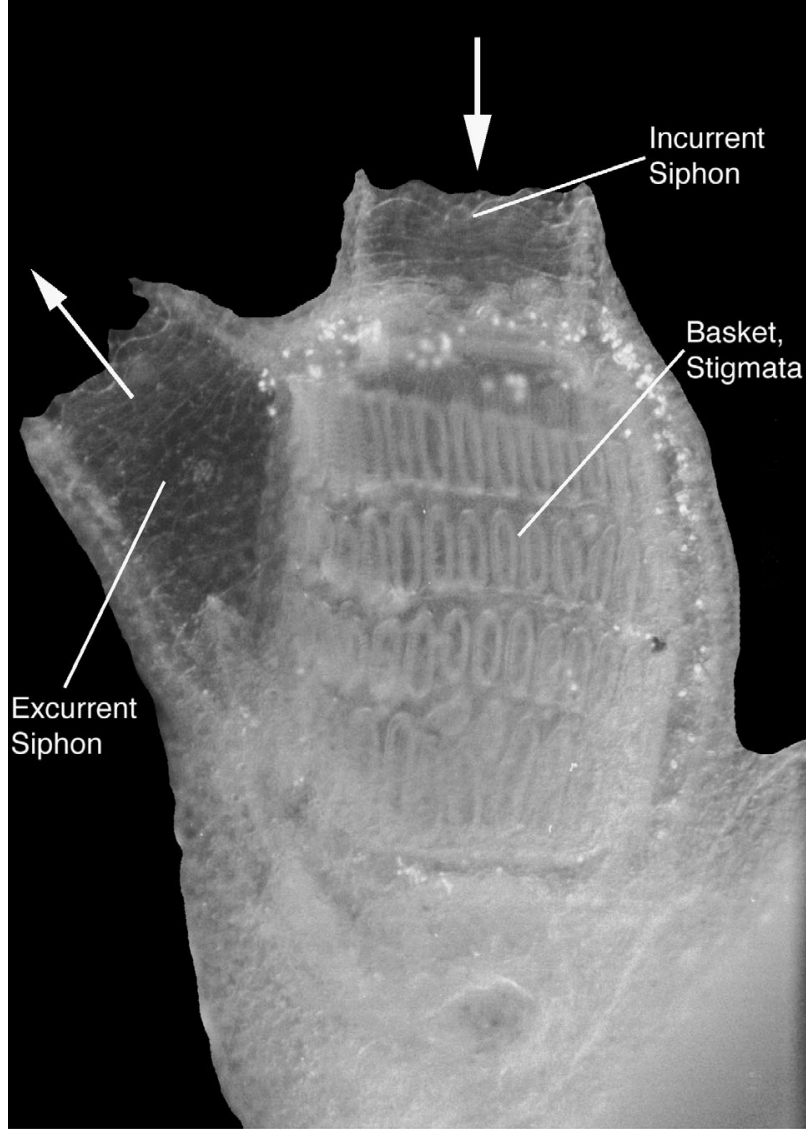

Fig. 1. Photomicrograph of $4 \mathrm{~d}$ old Distaplia occidentalis oozooid in lateral view, approximately $1 \mathrm{~mm}$ high. Arrows indicate direction of water flow. Cilia within the stigmata drive flow. Particles are captured on a finely meshed mucous net lining the inside of the branchial basket. The net is continually secreted at the ventral side (right), moved dorsally by frontal cilia and swallowed on the lower dorsal side (left)

incurrent siphon radius. Although the HagenPoiseuille equation is a more familiar estimate of pressure drop, Eq. (2) is a more appropriate estimate of the resistance to flow through the short siphons, in which length is typically $1 / 10$ to $1 / 5$ of diameter. For adult Ciona, whose siphons are sufficiently long that the HagenPoiseuille equation is appropriate (Loudon \& McCulloh 1999), we calculated siphonal pressure drop as (Vogel 1994):

$$
\Delta P_{\text {siph }}=\frac{8 \mu Q L}{\pi r^{4}}
$$

where $Q=$ volumetric flow rate, $L=$ incurrent siphon length and $r=$ incurrent siphon radius. Because frictional pressure drop through the basket and excurrent siphon is less but not negligible, Eqs. (2) \& (3) provide a conservative estimate of total frictional pressure drop. 
Pump power calculations were made from:

$$
\mathrm{W}_{\text {siph }}=Q \Delta P_{\text {siph }}=3 \mu r \pi^{2} V^{2}
$$

(Vogel 1994). This method underestimates power requirements for larger subadults, for whom siphonal pressure drop is only 30 to $60 \%$ of total pressure drop, but is reasonable for small juveniles, for whom siphonal pressure drop is greater than $90 \%$ of the total.

Scaling and statistics. Scaling, or how the form or function of an animal changes as its size changes, is quantified by plotting the logarithm of the variable of interest against the logarithm of size. We report reduced major axis (RMA) slopes for flow rate variables versus linear size. We calculated $r$ (Pearson's correlation coefficient) and the probability ( $p$-value) that $r$ was significantly different from zero in Statview 5.0, and used a bootstrapping method to estimate $95 \%$ BCa (bias-corrected and accelerated) confidence intervals of RMA slopes and to evaluate significant differences of species pairs (see Sherrard \& LaBarbera 2005) for details). Even when p-values for relationships were not significant, the RMA permutations test (Efron \& Tibshirani 1986) for differences between species remains valid.

Based on assumptions of geometric isometry, volumetric flow rate should scale as length ${ }^{2}$ or mass ${ }^{0.67}$ because the area of ciliated stigmata, which are responsible for driving flow, scales as length ${ }^{2}$ in ascidians (Petersen \& Svane 2002, Sherrard \& LaBarbera 2005). If volumetric flow rate scales as length ${ }^{2}$, functional equivalence with metabolic rate would also be maintained, which generally scales as mass ${ }^{0.67}$ or length ${ }^{2}$ within a species' on- togeny (Zeuthen 1953, Schmidt-Nielsen 1970). However, these considerations do not take into account the possible decrease in volumetric flow rate that might occur in small juveniles due to their inordinately high siphonal resistance or to developmental factors.

Because siphonal pressure drop is the product of volumetric flow rate and siphonal resistance (which scales as length $^{-3}$, inversely proportional to siphonal radius cubed; see Sherrard \& LaBarbera 2005), the isometric prediction is for siphonal pressure drop to scale as length $^{-1}$. Likewise, pump power is the product of volumetric flow and pressure drop, and thus the isometric prediction is that it scales as length ${ }^{1}$.

\section{RESULTS}

We analyzed early juveniles and subadults of solitary species separately, as described in Sherrard \& LaBarbera (2005). In colonial species, oozooids (the single zooid resulting from metamorphosis of the larva) had similar scaling throughout their ontogeny and are also termed early juveniles.

\section{Early juvenile flow rates}

Volumetric flow rates in early juveniles of colonial and solitary species all exhibited strong positive allometry (Table 1, Fig. 2). In contrast, subadults and adults of solitary species displayed isometric or nearly isomet-

Table 1. Scaling of flow rate $\left(Q, \mathrm{ml} \mathrm{s}^{-1}\right)$, siphonal pressure drop $\left(\Delta P_{\mathrm{siph}}, \mathrm{Pa}\right)$, and pump power required to drive flow through siphons $\left(W_{\text {siph }}, \mathrm{W}\right)$ with linear size $L$ (square root of lateral body area, $\mathrm{mm}$ ). Isometry: isometric expectation under an assumption of geometric similarity. EJ: early juvenile, defined by strongly allometric increases in flow rate (see Fig. 2) during the completion of metamorphosis in the first few weeks of juvenile life. 95\% confidence intervals shown under reduced major axis (RMA) slopes. LS: least squares slope. ns: correlation coefficient not significantly different from $0 .{ }^{a}$ Significant positive allometry based on $95 \%$ confidence limits; ${ }^{b}$ significant negative allometry. ${ }^{*}$ p-value for regression only marginally significant (p: 0.0688)

\begin{tabular}{|c|c|c|c|c|c|c|c|c|c|c|c|c|}
\hline \multirow{3}{*}{$\begin{array}{l}\text { Species } \\
\text { Isometry }\end{array}$} & \multicolumn{4}{|c|}{$Q$ vs. $L$} & \multicolumn{4}{|c|}{$-\Delta P_{\text {siph }}$ vs. $L$} & \multicolumn{4}{|c|}{$-W_{\text {siph }}$ vs. $L-$} \\
\hline & RMA & LS & $r^{2}$ & $\mathrm{~N}$ & RMA & LS & $r^{2}$ & $\mathrm{~N}$ & RMA & LS & $r^{2}$ & $\mathrm{~N}$ \\
\hline & 2 & 2 & & & -1 & -1 & & & 1 & 1 & & \\
\hline Botrylloides & $\begin{array}{c}7.5^{\mathrm{a}} \\
6.6-8.6\end{array}$ & $6.7^{\mathrm{a}}$ & 0.79 & 38 & $\begin{array}{c}3.5^{\mathrm{b}} \\
2.3-4.9\end{array}$ & $1.8^{\mathrm{b}}$ & 0.27 & 38 & $\begin{array}{c}10.0^{\mathrm{a}} \\
8.2-12.5\end{array}$ & $8.2^{\mathrm{a}}$ & 0.66 & 38 \\
\hline Distaplia & $\begin{array}{c}5.0^{\mathrm{a}} \\
4.4-5.7\end{array}$ & $4.5^{\mathrm{a}}$ & 0.74 & 20 & ns & 0.3 & 0.02 & 20 & $\begin{array}{c}4.9^{\mathrm{a}} \\
4.0-5.8\end{array}$ & $4.4^{\mathrm{a}}$ & 0.8 & 20 \\
\hline Corella EJ & $\begin{array}{c}5.3^{\mathrm{a}} \\
4.2-8.5\end{array}$ & $4.6^{\mathrm{a}}$ & 0.74 & 10 & ns & -1.2 & 0.15 & 10 & $\begin{array}{c}5.2^{\mathrm{a}} \\
2.5-9.7\end{array}$ & 3.4 & 0.42 & 10 \\
\hline Ciona EJ & $\begin{array}{c}5.6^{\mathrm{a} *} \\
2.4-9.1\end{array}$ & $4.5^{\mathrm{a}}$ & 0.78 & 12 & ns & $1^{\mathrm{b}}$ & 0.27 & 12 & $\begin{array}{c}7.2^{\mathrm{a}} \\
3.7-22.0\end{array}$ & $5.4^{\mathrm{a}}$ & 0.57 & 12 \\
\hline Corella & $\begin{array}{c}2.6^{\mathrm{a}} \\
2.4-3.0\end{array}$ & $2.6^{\mathrm{a}}$ & 0.97 & 29 & $\begin{array}{c}-0.9 \\
-0.6 \text { to }-1.4\end{array}$ & -0.6 & 0.59 & 29 & $\begin{array}{c}2.1^{\mathrm{a}} \\
1.8-2.5\end{array}$ & $1.9^{\mathrm{a}}$ & 0.85 & 29 \\
\hline Ciona & $\begin{array}{c}2.2^{\mathrm{a}} \\
2.03-2.3\end{array}$ & 2.1 & 0.99 & 19 & $\begin{array}{c}-0.5^{\mathrm{b}} \\
-0.4 \text { to }-0.6\end{array}$ & $-0.5^{b}$ & 0.86 & 19 & $\begin{array}{c}1.7^{\mathrm{a}} \\
1.5-1.9\end{array}$ & $1.7^{\mathrm{a}}$ & 0.95 & 19 \\
\hline
\end{tabular}




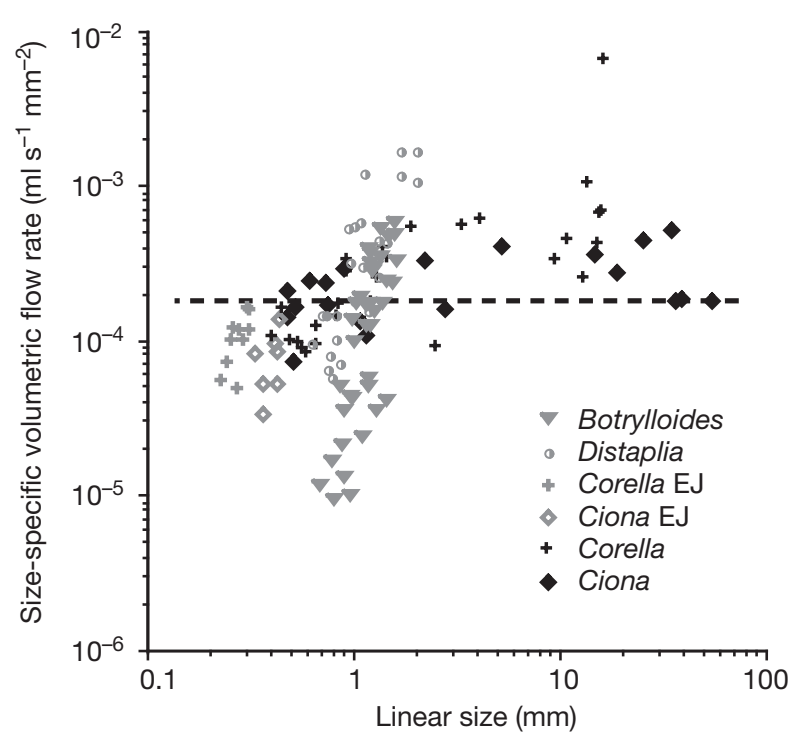

Fig. 2. Size-specific volumetric flow rates $\left(\mathrm{ml} \mathrm{s}^{-1} \mathrm{~mm}^{-2}\right)$ in the ontogeny of solitary and colonial ascidians. Early juvenile volumetric flow rates are depressed relative to those of larger conspecifics across a wide range of initial juvenile sizes and exhibit strongly positively allometric scaling (see Table 1). This implies that early juveniles are limited by developmental stage rather than by size. Note that Corella began feeding at a smaller size than Ciona and switched to isometric growth earlier. The colonial species Botrylloides had volumetric flow rates lower or equivalent to solitary juveniles in the same size range, whereas Distaplia had equivalent or higher volumetric flow rates. Dotted line shows the minimal level attained by solitary adults

ric increases in volumetric flow rate. Scaling of volumetric flow rate was significantly higher in solitary early juveniles than in solitary subadults, as it was in subadults of Corella than in Ciona subadults $(\mathrm{p}<$ 0.0001, permutations test; unless noted, p-values are from the permutations test, after Efron \& Tibshirani 1986). Flow rate scaling was not significantly different between Corella and Ciona early juveniles or Botrylloides and Distaplia early juveniles (Fig. 2), but it did exhibit significantly steeper positive allometry in Botrylloides than in Corella early juveniles $(p=0.002)$ and in Ciona early juveniles $(p=0.026)$. Regressions of volumetric flow rate versus size in early juveniles had lower correlation coefficients than in subadults, partly due to their smaller size range but also in the colonial species because their morphology and volumetric flow rates were more variable among individuals.

The solitary species shifted to isometric or nearly isometric scaling of volumetric flow rate at different ages, sizes and developmental stages. In Corella, the transition occurred at 10 to $12 \mathrm{~d}$, a time when the 2 pairs of protostigmata begin to divide. In Ciona, this scaling transition occurred at 16 to $20 \mathrm{~d}$, when there were already 4 pairs of stigmata and the incurrent siphon ceased allometric expansion (Sherrard \& LaBarbera 2005). The transition did not correspond to a shift in hydrodynamic regime: Corella and Ciona early juveniles had a minimum siphonal Re of 0.04 and shifted to isometric increases at Re's of 0.3 to 0.5 , still well within the viscous range. Corella subadults and adults continued to have positively allometric scaling in volumetric flow rates throughout ontogeny. In Ciona subadults and adults, flow rate scaled with slight but significant positive allometry.

Botrylloides blastozooids had volumetric flow rates and sizes indistinguishable from those of the oozooids (data on colonial blastozooids not shown). In Distaplia, functional blastozooids had higher volumetric flow rates than oozooids, but their lateral area could not be reliably determined due to colony opacity so it is not clear whether size difference is responsible. Siphonal Re's were 0.03 to 3 in Botrylloides oozooids and blastozooids, and 0.2 to 3 in Distaplia oozooids, with Distaplia blastozooids reaching an Re of 8 .

In Botrylloides oozooids, volumetric flow rates relative to body size were initially lower and became comparable to the solitary species', whereas they were initially comparable and became higher in older oozooids of Distaplia (Fig. 2). Distaplia had slightly but not significantly higher volumetric flow rates than Botrylloides.

\section{Siphonal pressure drop and pump power requirements in early juveniles}

Incurrent siphon pressure drop $\left(\Delta P_{\text {siph }}\right)$ scaled with negative allometry in all groups for which the relationship was significant (Table 1, Fig. 3). Values of the correlation coefficient were generally low for this regression and $p$-values from regressions coefficients indicate that the slopes were not significantly different from 0 for solitary early juveniles and Distaplia oozooids. The lack of a significant relationship between pressure drop and body size in early juveniles is likely due to their small size range.

Siphonal pressure drop appeared to increase in early juveniles, corresponding to their rapid increases in volumetric flow rate, but decreased isometrically or nearly so in subadults of the solitary species (Table 1). Siphonal pressure drop decreased significantly faster in Corella subadults than in Ciona subadults $(\mathrm{p}<0.001)$. It increased significantly faster in colonial early juveniles than in solitary early juveniles (except for Ciona and Distaplia, which were not significantly different). Siphonal pressure drop was several times higher in some Corella and Distaplia early juveniles than maximal values observed in subadults and adults (Fig. 3). 
Siphonal pump power $\left(W_{\text {siph }}\right)$, the product of volumetric flow rate and siphonal pressure drop, increased with positive allometry in all groups except early juvenile Corella, for which the trend was not significant (Fig. 4, Table 1). Botrylloides oozooids had a significantly steeper slope than Distaplia and Corella early juveniles ( $\mathrm{p} \leq 0.001)$, and all early juveniles other than Corella had significantly steeper slopes than Corella and Ciona subadults $(\mathrm{p} \leq 0.001)$.

\section{Juvenile-specific means of particle rejection}

Early juveniles of Corella and Ciona feed in a viscous fluid regime of $\mathrm{Re}=0.05$ to 0.5 . They were able to remotely detect particles the size of Rhodamonas ( $8 \mu \mathrm{m}$, approximately $1 / 8$ siphon diameter) as shown by their occasional rejection of these particles while the algal cells were still several siphon radii from the siphon entrance. Juveniles attempted rejection by stopping the feeding current. Typical of low Re fluid behavior, cessation of ciliary beat caused the unwanted particle to stop immediately. In moving water, a particle would probably drift away during this pause

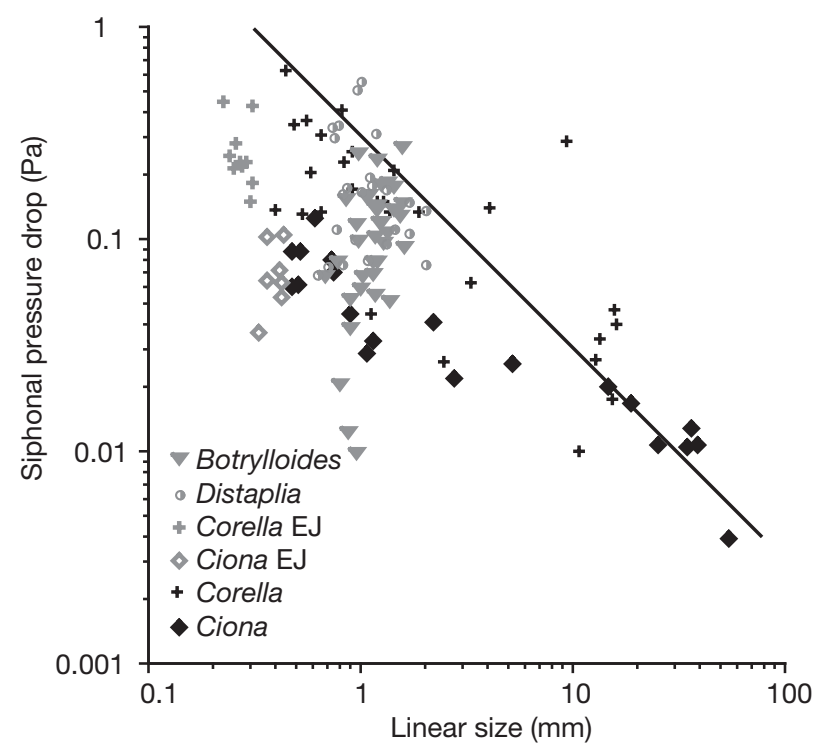

Fig. 3. Ontogenetic scaling of incurrent siphonal pressure drop (Pa) with linear size (square root of body area, $\mathrm{mm}$ ). Isometric line drawn for reference at elevation occupied by adults. Corella and Distaplia early juveniles had substantially higher values than the other species and ages, and Corella subadults also had higher and more variable pressure drops than Ciona (see Table 1). Total pressure drops would be approximately 2 to 3 times higher in adults if mucous net and exit jet pressure drops were included; however, these terms are inconsequential in early juveniles compared with incurrent siphonal pressure drop. The higher pressure drop in adult Ciona than Corella is due to higher resistance in the longer siphons of adults

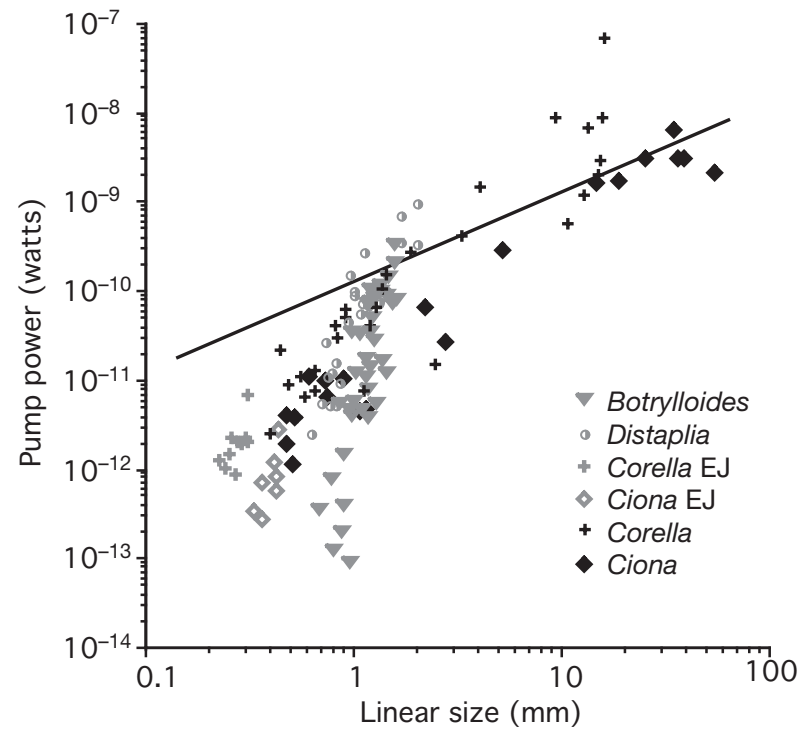

Fig. 4. Ontogenetic scaling of pump power requirements (W) with linear size $(\mathrm{mm})$. Pump power is calculated as the product of siphonal pressure drop and volumetric flow rate. Corella required higher power than Ciona throughout its ontogeny and Distaplia zooids required higher power than Botrylloides zooids. Conventions as in Fig. 3

in feeding. However, particles did not drift in the small chamber used for videomicroscopy and, when feeding resumed, the particle again was drawn towards the basket. Sometimes rejection was attempted several times, or a particle that had entered the siphon was ejected by siphon contraction. We never observed older solitary juveniles or juveniles of colonial species rejecting particles before they entered the siphon, but we did not search for this behavior systematically.

In several Ciona and Corella early juveniles, we observed another type of rejection (not necessarily intentional), in which particles entered the incurrent siphon and were immediately ejected from the excurrent siphon. For this to occur, the mucous net must have been torn or was not being secreted. This behavior was not observed frequently enough to ascertain the circumstances associated with it. We observed individuals who fed normally on days before and after exhibiting this rejection behavior. The behavior would be difficult to detect in adults, because, when observing the excurrent siphon under a microscope, magnifications are not high enough to see individual particles exiting.

\section{DISCUSSION}

An enduring issue in biology concerns the effects of size change, whether ontogenetic or evolutionary, on function. Much work has focussed on the difficulties of 
becoming large, whereas the challenges of beginning small have received less attention. Yet temporary smallness is a common state: for example, the majority of marine invertebrates commence adult lifestyles while at microscopic size. Many of these suspension feed, but to our knowledge this is the first study of feeding flow rates in early juvenile marine invertebrates.

\section{Volumetric flow rates in early juveniles versus later stages}

Early juveniles of the 4 species investigated here displayed a strong positive allometry in volumetric flow rate relative to size, meaning that smaller animals feed less efficiently than larger ones. The disproportionately high resistance to flow through the siphons of early juveniles, which persists for the same period of early juvenile growth (see Sherrard \& LaBarbera 2005), is likely to be the primary cause of their lower volumetric flow rates. Juvenile siphonal resistance was higher because the siphons of newly metamorphosed juveniles were initially narrow, requiring several days to a week to expand to adult proportions. This is part of a process that has been recognized in ascidians, termed 'secondary metamorphosis' (Berrill 1947, Davidson et al. 2003).

On the other hand, the extensive ontogenetic changes in stigmatal shape in Ciona and Corella (Damas 1900, Huntsman 1913, Selys-Longchamps 1913) do not appear to affect their scaling of volumetric flow rates. In a comparative study of adult ascidians with varied stigmatal form, Petersen \& Svane (2002) also found no effect of stigmatal shape on volumetric flow rate; only the total stigmatal perimeter mattered. In ascidians, ciliary size, number, placement and density within the stigmata is highly conserved (Monniot 1979, Dallai et al. 1985, Martinucci et al. 1987), as would be expected from optimality considerations for pumping (Grunbaum et al. 1998). Ciliary length and stigmatal width were identical throughout ontogeny in the species studied here (data not shown) and stigmatal perimeter increased isometrically in early juveniles (Sherrard \& LaBarbera 2005). Thus, unless there was a difference in ciliary density in these early stages, stigmatal growth cannot contribute to the observed allometric scaling of volumetric flow rates in early juveniles. However, positive allometry in stigmatal perimeter in older juveniles and adults of Corella and Ciona (Sherrard \& LaBarbera 2005) does correspond to positively allometric increases in volumetric flow rate.

Lambert (1967) noted that when Corella inflata (formerly called Corella willmeriana) had attained 450 to
$550 \mu \mathrm{m}$ in body length and 10 to 13 stigmata, they exhibited a sudden, dramatic increase in growth rates. She postulated that attaining this number of stigmata increased the feeding flow rate, although she did not measure flow rates directly. We did indeed observe a jump in volumetric flow rates at this size, corresponding to our division into early juveniles and subadults. However, we observed no increase in stigmatal perimeter at this size (Sherrard \& LaBarbera 2005); instead we postulate that the concurrent attainment of adult dimensions in the incurrent siphon accounts for the increased flow rates.

Siphonal pressure drops actually increased with size in early juveniles, as volumetric flow rates initially increased faster than siphonal resistance decreased. By the time juveniles of solitary species had grown to the size of colonial species' oozooids, their siphonal pressure drops had begun to decrease. Distaplia had higher pressure drops than Botrylloides, corresponding to higher volumetric flow rates. Corella juveniles had higher pressure drops than Ciona juveniles, due both to Corella's higher flow rates and relatively smaller siphons.

The positively allometric scaling of siphonal pump power requirements means that early juveniles used relatively less pump power to generate flow than later stages did. In fact, lower pump power requirements may be necessary in smaller animals if they are not to use too much of their energy budget for pumping fluid; because their resistance is relatively higher, their volumetric flow rates would have to be kept relatively lower.

Corella and Distaplia operated at a higher pump power while feeding at a higher rate, whereas Ciona and Botrylloides operated at a lower pump power and fed at a lower rate. These species pairs may optimize early feeding strategies in different ways. Corella and Distaplia might compete better under more dilute food conditions, where food concentration strongly limits growth, whereas Ciona and Botrylloides may require higher food concentrations. Interestingly, Ciona and Botrylloides are both invasive species in the NE Pacific. Investigating the sort of limitations on juvenile feeding suggested by these findings may help predict which local habitats are likely to be vulnerable to invasion.

To further assess functional constraints on feeding and growth in solitary ascidians, the ontogenetic scaling of volumetric flow rates in stolidobranch species such as Boltenia villosa and Styela gibbisi should be investigated. Juveniles of these species grow much more slowly than phlebobranch juveniles (Jacobs \& Sherrard 2002, Sherrard 2003), and have a flattened morphology, a tough tunic which may limit growth rate and a small, flattened basket. Resistance is higher than 
in all but the smallest Corella for a much longer period of time and it is likely that volumetric flow rates are depressed for a much longer time in ontogeny.

\section{No specializations for feeding at small size}

Colonial species did not display strong advantages in suspension feeding compared with solitary species. The similar positively allometric scaling observed in early juveniles of colonial and solitary species, despite their different sizes, suggests that developmental processes such as siphon expansion may influence early feeding performance more than size. It is surprising that oozooids are not specialized for feeding at small size, given that they share a genome with blastozooids, which are presumably adapted for feeding at sizes on the order of a millimeter.

Oozooids of the 2 colonial species differed, with Distaplia appearing more specialized for juvenile feeding performance than Botrylloides. Distaplia undergoes a rapid metamorphosis, beginning feeding within 30 min of settlement, whereas Botrylloides requires 12 to $24 \mathrm{~h}$ to begin feeding. However, feeding flow rates of colonial oozooids were similar to solitary juveniles in the same size range; only the oldest Distaplia oozooids had higher volumetric flow rates.

Table 2. Mass-specific volumetric flow rates in adult ascidians. Values from the literature and from the present study (lateral body areas transformed to dry masses using the empirical equation dry mass $=2.347 \times$ area $^{1.47}, r^{2}=0.942$ )

\begin{tabular}{|c|c|c|c|}
\hline Species & $\begin{array}{l}\text { Dry mass } \\
\text { (mg) }\end{array}$ & $\begin{array}{c}\text { Mass-specific } Q \\
\left(\mathrm{ml} \mathrm{h}^{-1} \mathrm{~g}^{-1}\right)\end{array}$ & Source \\
\hline Corella inflata & 4.3 & 45654 & \multirow{11}{*}{ Present study } \\
\hline Corella inflata & 6.9 & 22789 & \\
\hline Corella inflata & 10 & 35673 & \\
\hline Corella inflata & 10.4 & 69388 & \\
\hline Corella inflata & 10.8 & 60075 & \\
\hline Ciona savigyi & 9.8 & 29358 & \\
\hline Ciona savigyi & 39.6 & 25636 & \\
\hline Ciona savigyi & 114.5 & 7497 & \\
\hline Ciona savigyi & 166.1 & 13503 & \\
\hline Ciona savigyi & 168.8 & 6014 & \\
\hline Ciona savigyi & 285.1 & 6826 & \\
\hline Ascidia mentula & 300 & 23760 & Jørgensen et al. (1984) \\
\hline Ciona intestinalis & $\begin{array}{r}33 \\
700\end{array}$ & $\begin{array}{l}4728 \\
2743\end{array}$ & Randløv \& Riisgård (1979) \\
\hline Ciona intestinalis & 328 & $\begin{array}{l}2745 \\
3303\end{array}$ & \multirow{8}{*}{ Fiala-Medioni (1978c) } \\
\hline Ciona intestinalis & 334 & 4473 & \\
\hline Styela plicata & 1291 & 3430 & \\
\hline Styela plicata & 1369 & 3156 & \\
\hline Styela plicata & 1888 & 3280 & \\
\hline Phallusia mammalata & 2567 & 1669 & \\
\hline Phallusia mammalata & 3112 & 1249 & \\
\hline Phallusia mammalata & 4546 & 895 & \\
\hline
\end{tabular}

Solitary species also displayed little evidence of specialization to feeding at the smallest size. Although morphological features such as short siphons and Ciona's stalk and wider siphons mitigated problems associated with suspension feeding at small size (Sherrard \& LaBarbera 2005), these were insufficient to boost early juvenile volumetric flow rates to isometric levels until the third week post-settlement or later. Newly settled solitary juveniles were $200 \mu \mathrm{m}$ long, the same size as early juvenile bivalves (Chanley \& Andrews 1971), suggesting this may represent a general lower size limit to active, internal suspension feeding using ciliary pumps. The fact that solitary ascidians produce many tiny juveniles, most of which do not survive, may mean that selection on life histories has not led to the optimization of juvenile feeding performance in these species.

\section{Early juvenile particle rejection behavior}

Rejection of particles by juveniles is both enabled and complicated by the low Reynolds number regime and life deep within a velocity boundary layer. Solitary juveniles had a unique ability to detect individual particles, an ability which is lost once animals reach about a millimeter in length. However, presumably because they had so little basket volume, they were unable to eject the particle more than a siphon radius away and often ingested it subsequently. This type of rejection may work better in flowing water, but for small animals attached to substrate, the boundary layer may frustrate rejection.

Early juvenile mechanisms of rejection may be adaptive in preventing the ingestion of harmful particles (such as parasitic copepods) or particles too large to fit in the esophagus. However, the fact that no colonial ascidians have zooids as small as early juveniles of solitary species suggests that the disadvantages of suspension feeding at such small size outweigh any possible advantages of remote particle detection.

\section{Comparison with other published flow rates}

Our values for adult Corella inflata and Ciona savignyi (lateral body area was converted to dry mass using the empirical RMA regression equation dry 


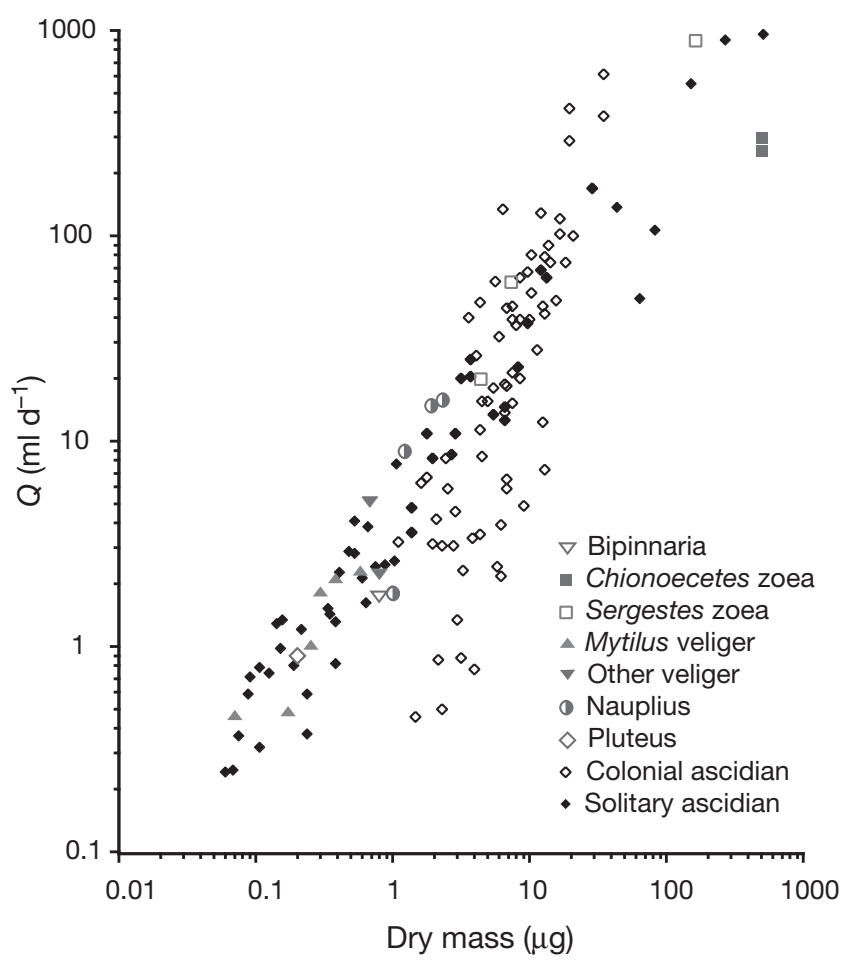

Fig. 5. Volumetric flow rates $\left(\mathrm{ml} \mathrm{d}^{-1}\right)$ versus dry mass $(\mu \mathrm{g})$ in juvenile ascidians and larval suspension feeders. Larval forms fall in the same range as juvenile ascidians of solitary species, despite the different modes of suspension feeding (various forms of ciliary capture in swimming larvae, as opposed to mucous net sieving combined with ciliary pumping in sessile ascidians). Only the early juveniles of colonial species fell below the overall regression, perhaps because, despite their large size, their flow rates are decremented while they complete metamorphosis. The increased resistance faced by ascidians pumping through small siphons and across a finely meshed mucous net may be compensated by the greater efficiency of suspension feeding while sessile, and the high retention efficiency of the mucous net compared with active ciliary capture. Clearance rate data for larvae from Hart \& Strathmann (1995, their Fig. 1)

mass $=2.347 \times \operatorname{area}^{1.47}\left(\mathrm{r}^{2}=0.956\right.$; Sherrard \& LaBarbera 2005) agreed reasonably well with published values for adult ascidians feeding at 10 to $15^{\circ} \mathrm{C}$ (Table 2). Use of hot film probes to measure excurrent flow (Fiala-Medioni 1978a, 1978b) and flow estimates based on clearance rates (Randløv \& Riisgård 1979, Jørgensen et al. 1984) both tend to underestimate volumetric flow rates by 25 to $40 \%$ (Charriaud 1982) compared with the direct method employed here. Additionally, smaller animals such as the $C$. inflata measured here have intrinsically higher mass-specific volumetric flow rates, since volumetric flow rate scales as mass ${ }^{0.8}$ (Randløv \& Riisgård 1979, this paper).

Since early juvenile ascidians are of a similar size to planktotrophic larvae, it is of interest to compare their volumetric flow rates. Hart \& Strathmann (1995) compiled literature values of volumetric flow rates (based on clearance rates) and dry masses for a variety of larval suspension feeders. Mass-specific volumetric flow rates are in the same range for these larvae and juvenile ascidians (Fig. 5). This is somewhat surprising, since larvae swim while they suspension feed, which tends to reduce shear rates and capture efficiency compared with a tethered or sessile form (Hart \& Strathmann 1995).

\section{CONCLUSIONS}

Early juvenile ascidians of the 4 species investigated here had relatively and, in many cases, absolutely higher pressure drops and resistance than conspecific subadults and adults. Correspondingly, they had lower volumetric flow rates than would be predicted from geometric isometry. Despite high juvenile mortality rates and the advantages of rapid growth, selection on early juvenile stages has evidently not improved their feeding performance to the level of later stages.

Developmental stage appears to be more important than size in determining early juvenile suspension feeding performance. High siphonal resistance, even combined with relatively lower volumetric flow rates, caused rapid increases in pressure drops and pump power requirements in newly settled juveniles of a wide range of sizes. Attainment of volumetric flow rates comparable to those of adults occurred early; however, 1 to $2 \mathrm{wk}$ after the commencement of feeding regardless of size. In addition to the risks of predation, mechanical damage and disease faced by early juveniles, their feeding mechanism is inherently less efficient than that of older animals, which is likely to reduce growth rates and lengthen the time spent at the most vulnerable sizes.

It was surprising that juveniles of colonial species had no better size-specific feeding performance than solitary species, given their opportunity to specialize as small suspension feeders. Their larger initial size and precocious development of feeding structures may nevertheless make them better competitors for space, reduce the time spent at the size of greatest vulnerability and lessen the time from settlement to reproductive maturity.

Acknowledgements. We thank D. Grunbaum, C. Pfister, J. Voight, J. Socha and 3 anonymous reviewers for helpful comments on the manuscript. We are grateful to A. O. D. Willows and the staff of Friday Harbor Laboratories for making facilities available for this research. The work was part of K.S.'s doctoral dissertation and was funded by the University of Chicago Hinds fund, a Friday Harbor Labs Alan Kohn Fellowship, a Sigma Xi Grant-in-Aid-of-Research, a Society for Inte- 
grative and Comparative Biology Grant-in-Aid-of-Research, and an NSF Doctoral Dissertation Improvement Grant (\# 0206026).

\section{LITERATURE CITED}

Armsworthy SL, MacDonald BA, Ward JE (2001) Feeding activity, absorption efficiency and suspension feeding processes in the ascidian, Halocynthia pyriformis (Stolidobranchia: Ascidiacea): responses to variations in diet quantity and quality. J Exp Mar Biol Ecol 260:41-69

Beninger PG, Dwiono SAP, Pennec ML (1994) Early development of the gill and implications for feeding in Pecten maximus (Bivalvia: Pectinidae). Mar Biol 119:405-412

Berrill NJ (1947) The development and growth of Ciona. J Mar Biol Assoc UK 26:616-625

Chanley P, Andrews JD (1971) Aids for identification of bivalve larvae of Virginia. Malacologia 11(1):45-119

Chaparro OR, Videla JA, Thompson RJ (2001) Gill morphogenesis in the oyster Ostrea chilensis. Mar Biol 138: 199-207

Charriaud E (1982) Direct measurements of velocity profiles and fluxes at the cloacal siphon of the ascidian Ascidiella aspersa. Mar Biol 70:35-40

Dallai R, Burighel P, Martinucci GB (1985) Ciliary differentiations in the branchial stigmata of the ascidian Diplosoma listerianum. J Submicrosc Cytol 17(3):381-390

Damas D (1900) Etude du sac branchial chez Ciona intestinalis (L.). Arch Biol 17:1-32

Davidson B, Smith Wallace SE, Howsmon R, Swalla BJ (2003) A morphological and genetic characterization of metamorphosis in the ascidian Boltenia villosa. Dev Genes Evol 213:601-611

Declerck CH (1995) The evolution of suspension feeding in gastropods. Biol Rev Camb Phil Soc 70:549-569

de Selys-Longchamps M (1913) Evolution des stigmates branchiaux chez les ascides du genre Corella. Ann Soc Zool Belg 48:127-139

Efron B, Tibshirani RJ (1986) Bootstrap methods for standard errors, confidence intervals, and other measures of statistical accuracy. Stat Sci 1:54-77

Fiala-Medioni A (1978a) Filter-feeding ethology of benthic invertebrates (ascidians). III. Recording of water current in situ - Rate and rhythm of pumping. Mar Biol 45:185-190

Fiala-Medioni A (1978b) Filter-feeding ethology of benthic invertebrates (Ascidians). IV. Pumping rate, filtration rate, filtration efficiency. Mar Biol 48:243-249

Fiala-Medioni A (1978c) Filter-feeding ethology of benthic invertebrates (ascidians). V. Influence of temperature on pumping, filtration and digestion - Rates and rhythms in Phallusia mamillata. Mar Biol 48:251-259

Gosselin LA, Qian PY (1997) Juvenile mortality in benthic marine invertebrates. Mar Ecol Prog Ser 146:265-282

Grunbaum D, Eyre D, Fogelson A (1998) Functional geometry of ciliated tentacular arrays in active suspension feeders. J Exp Biol 201:2575-2589

Hart MW, Strathmann RR (1995) Mechanisms and rates of suspension feeding. In: McEdward L (ed) Ecology of marine invertebrate larvae. CRC Press, Boca Raton, FL, p 193-221

Editorial responsibility: Otto Kinne (Editor-in-Chief), Oldendorf/Luhe, Germany
Hunt HL, Scheibling RE (1997) Role of early post-settlement mortality in recruitment of benthic marine invertebrates. Mar Ecol Prog Ser 155:269-301

Huntsman AG (1913) Protostigmata in ascidians. Proc R Soc Lond, B 86:440-453

Jacobs MW, Sherrard KM (2002) Shape matters: the effect of nutritional stress on juvenile growth rates of four species of ascidians. Am Zool 41(6)

Jørgensen CB, Kiørboe T, Mohlenberg F, Riisgård HU (1984) Ciliary and mucous-net filter feeding, with special reference to fluid mechanical characteristics. Mar Ecol Prog Ser 15:283-292

Lambert G (1967) Some aspects of the general ecology and growth of the solitary ascidian Corella willmeriana. MSc thesis, University of Washington, Seattle

Lesser MP, Witman JD, Sebens KP (1994) Effects of flow and seston availability on scope for growth of benthic suspension-feeding invertebrates from the Gulf of Maine. Biol Bull 187:319-335

Loudon C, McCulloh K (1999) Application of the HagenPoiseuille equation to fluid feeding through short tubes. Ann Entomol Soc Am 92(1):153-158

Martinucci GB, Dallai R, Burighel P (1987) A comparative study of ciliary differentiations in the branchial stigmata of ascidians. Tissue Cell 19(2):251-263

Monniot F (1979) Microfiltres et ciliatures branchiales des ascidies littorales en microscopie electronique. Bull Mus Nation Hist Nat Paris A 4:843-859 (in French with English abstract)

Moran AL, Emlet RB (2001) Offspring size and performance in variable environments. Ecology 82(6):1597-1612

Osman RW, Whitlatch RB (1996) Processes affecting newlysettled juveniles and the consequences to subsequent community development. Invertebr Reprod Dev 30:217-225

Paulay G, Boring L, Strathmann RR (1985) Food limited growth and development of larvae: experiments with natural sea water. J Exp Mar Biol Ecol 93:1-10

Petersen JK, Svane I (2002) Filtration rate in seven Scandinavian ascidians: implications of the morphology of the gill. Mar Biol 140:397-402

Randløv A, Riisgård HU (1979) Efficiency of particle retention and filtration rate in four species of Ascidians. Mar Ecol Prog Ser 1:55-59

Riisgård HU (1988) The ascidian pump: properties and energy cost. Mar Ecol Prog Ser 47:129-134

Schmidt-Nielsen K (1970) Animal physiology. Prentice-Hall, Englewood Cliffs, NJ

Sherrard KM (2003) A comparative study of early juvenile feeding performance in ascidians. $\mathrm{PhD}$ thesis, University of Chicago, Chicago

Sherrard KM, LaBarbera M (2005) Form and function in early juvenile ascidians. I. Implications of early juvenile morphologies for performance. Mar Ecol Prog Ser 287: $127-138$

Stoner DS (1990) Recruitment of a tropical colonial ascidian: relative importance of pre-settlement vs. post-settlement processes. Ecology 7(5):1682-1690

Vogel S (1994) Life in moving fluids. Princeton University Press, Princeton, NJ

Zeuthen E (1953) Oxygen uptake as related to body size in organisms. Q Rev Biol 28(1):1-12

Submitted: February 18, 2004; Accepted: June 29, 2004

Proofs received from author(s): February 4, 2005 